\title{
Evaluation of contrast nephropathy in percutaneous treatment of chronic total occlusions
}

\author{
ERDAL AKTÜRK ${ }^{1}$, LÜTFÜ AŞKIN ${ }^{1, *}$, HAKAN TAŞOLAR ${ }^{2}$, ERTUĞRUL KURTOĞLU $^{3}$, \\ SERDAR TÜRKMEN ${ }^{1}$, OKAN TANRIVERDI ${ }^{1}$, KADER ELIZ UZEL ${ }^{1}$ \\ ${ }^{1}$ Faculty of Medicine, Department of Cardiology, Adiyaman University, Adiyaman, Turkey \\ ${ }^{2}$ Faculty of Medicine, Department of Cardiology, Inönü University, Malatya, Turkey \\ ${ }^{3}$ Department of Cardiology, Malatya Training and Research Hospital, Malatya, Turkey \\ *Corresponding author: Lütfü Aşkın, MD; Department of Cardiology, Adiyaman University, Adiyaman 02000, Turkey; Phone: +90 5315203486 ; \\ Fax: +90 4161015; E-mail: lutfuaskin23@gmail.com
}

(Received: March 18, 2019; Revised manuscript received: April 3, 2019; Accepted: April 24, 2019)

\begin{abstract}
Background: Contrast-induced nephropathy (CIN) is a leading cause of morbidity and mortality in patients undergoing percutaneous coronary intervention (PCI). Chronic total occlusions (CTO) are frequently observed among patients undergoing coronary angiography. Methods: A total of 128 CTO patients were included. Mehran score, lesion characteristics, interventional procedure, serological specimens and devices were recorded. The first group was administered with $1 \mathrm{ml} \cdot \mathrm{kg}^{-1} \cdot \mathrm{h}^{-1}$ saline $(0.9 \% \mathrm{NaCl})$ infusion that started $12 \mathrm{~h}$ before the procedure and continued $12 \mathrm{~h}$ post procedure as recommended by the guidelines. The second group was administered with saline infusion of $12 \mathrm{ml} \cdot \mathrm{kg}^{-1} \cdot \mathrm{h}^{-1}$ only during CTO-PCI procedure, which is called as intensive infusion. Results: CIN development was similar in two groups (four patients in standard hydration group and five patients in intensive hydration group). The amount of saline was significantly higher in the standard group (1,767 \pm 192.2 vs. $1,043.6 \pm 375 ; p<0.001)$. Patients with higher creatinine levels prior to PCI had a higher rate of CIN development after procedure. Interestingly, age, left ventricular ejection fraction, and diabetes mellitus independently predicted CIN. Conclusion: Intensive hydration administration appears to be an effective and cost-effective method in CTO-PCI patients, especially in patients without left ventricular function failure.
\end{abstract}

Keywords: chronic total occlusions, contrast-induced nephropathy, hydration, percutaneous coronary intervention, saline infusion

\section{Introduction}

Coronary chronic total occlusions (CTOs) are defined as an occluded coronary segment with thrombolysis in myocardial infarction (TIMI) flow 0 for $\geq 3$ months duration $[1,2]$. CTOs are frequently observed among patients undergoing coronary angiography (CAG) during catheterization at a rate of $18 \%-52 \%$ [3-5]. Multiple reports have demonstrated that $\mathrm{CTO}$ revascularization has clinical benefit [6-10]. Over the years, progress has been made for the presentation and distribution of CTO percutaneous coronary intervention (PCI) methods [11-13]. With mounting CTO-PCI experience, both antegrade and retrograde methods have increased the success rate of the procedure $[12,13]$. Still, complex
CTO lesions hampered initial success rates with prolonged X-ray exposure and use of large volumes of contrast medium [14].

Contrast-induced nephropathy (CIN) was defined as an increase in the baseline serum creatinine ( $\mathrm{SCr}$ ) levels $0.5 \mathrm{mg} / \mathrm{dl}$ or $\geq 25 \%$ in the $48-72 \mathrm{~h}$ contrast medium exposure. The incidence of CIN in the general population is estimated to be between $1 \%$ and $6 \%$, and is even higher when CIN follows PCI [15]. Nevertheless, the CIN frequency was increased in patients with renal dysfunction and was greater than $50 \%$ in high-risk patients [16].

Based on previous reports, the incidence of CIN is approximately $6 \%-7 \%$ in after CTO-PCI [14]. CIN accounts for $11 \%$ of acute renal failure (ARF) cases

This is an open-access article distributed under the terms of the Creative Commons Attribution-NonCommercial 4.0 International License, which permits unrestricted use, distribution, and reproduction in any medium for non-commercial purposes, provided the original author and source are credited, a link to the CC License is provided, and changes - if any - are indicated. 
and is the third leading cause of hospital-acquired ARF, contributing to prolonged hospital stay [17] and increased medical costs $[18,19]$. The in-hospital mortality rate was $22 \%$ for patients who developed CIN, compared with only $1.4 \%$ of in-patients who did not develop CIN [20].

In this study, patients with CTO who were treated with PCI were randomized into two groups with the intention to investigate CIN development, which is an important cause of morbidity/mortality. The first group underwent standard saline infusion as recommended in the guidelines, and the second group underwent intensive saline infusion during long CTO-PCI application.

\section{Materials and Methods}

\section{Study population}

This study was a single-center, randomized, prospective trial that contains patients with documented CTO lesions with planned revascularization. Approval was obtained by the local ethics committee and the study was performed under the Declaration of Helsinki. All procedures were discussed with patients and informed consent was obtained in writing.

A total of 128 CTO patients were included in this study. All patients underwent first CAG for diagnosis, and the decision of PCI on CTO stenosis was established by at least two invasive cardiologists. CTO-PCI procedures were all performed through femoral artery. The radial artery was used in proper patients for cases requiring dual injection. Antegrade and retrograde operations were performed in separates sessions. Patient serological specimens were obtained for biochemical testing/comprehensive blood count. Before the procedure, left ventricular (LV) function was assessed by echocardiography. The age, body mass index, coronary risk factors, prior PCI, and coronary artery bypass grafting $(\mathrm{CABG})$ characteristics of all patients were recorded before the procedure. The duration of laboratory stay and dose of radiation were calculated. Collateral circulation was defined as TIMI. CTO lesion length was measured following bilateral simultaneous coronary injections in cases with collaterals from other coronary arteries to see the filling of both the proximal and the distal occluded artery. All subjects were analyzed using the Mehran risk scoring system for CIN [21]. Contrast volume, which is the variable of Mehran score, was calculated. All measurements of the total amount of fluid received and released by the patients were performed outside the angiography laboratory. The patients with deteriorated left ventricular ejection fraction (LVEF) were closely followed up in terms of heart failure (HF).

Exclusion criteria were: (1) end-stage renal failure; (2) recent myocardial infarction or unstable hemodynamics; (3) EF\% $\leq 35$; (4) anemia, blood loss, and hypotension (represent the modifiable risk factors for
CIN); (5) use of LV assist device or intra-aortic balloon pump; (6) age $\geq 75$ years, creatinine clearance $\geq 1.7$, glomerular filtration rate $(\mathrm{GFR}) \leq 60$; and (7) Mehran risk scoring, high and very high, in patients.

\section{Definitions}

CTO was defined as TIMI Grade 0 for more than 3 months, with the presence of typical angina, reversible myocardial ischaemia on thallium stress study or patients with CTO lesions.

The CTO length was calculated after bilateral simultaneous coronary injections or antegrade coronary injection and visualized by filling both the proximal and the distal occluded artery.

The success of angiography was determined by visual analysis in the presence of TIMI Grade 3 flow with less than $30 \%$ residual stenosis. The retrograde method was determined by guidewire introduction into the collateral channels. These are attached to the target CTO vessel and distal to the lesion. Aspirin and clopidogrel, along with heparin, were given to each patient before the procedure to reduce clotting. During the interventional procedure, either iohexol or iodixanol contrast agents was used.

Before the procedure, the estimated GFR (eGFR) was determined based on SCr levels, age, weight, and gender using the Cockcroft-Gault formula: eGFR ( $\mathrm{ml} / \mathrm{min} /$ $\left.1.73 \mathrm{~m}^{2}\right)=[(140$-age $) \times$ weight $] /(\mathrm{SCr} \times 72)(\times 0.85$, if the patient is female). SCr measurement was conducted $12 \mathrm{~h}$ before the procedure in group with standard saline and $4 \mathrm{~h}$ before the procedure in group with intensive saline. The measurements were conducted at the 12th and 48th $\mathrm{h}$ in both groups after procedure. The measurements were also conducted $72 \mathrm{~h}$ post-procedure when it was necessary. Extra SCr calculations were acquired in patients with an early SCr elevation or in patients with increased hospitalization for other confounders.

The patients were randomized into two groups. The first group of patients was administered $1 \mathrm{ml} \cdot \mathrm{kg}^{-1} \cdot \mathrm{h}^{-1}$ saline $[0.9 \%$ sodium chloride $(\mathrm{NaCl})]$ infusion that started $12 \mathrm{~h}$ before the procedure and continued $12 \mathrm{~h}$ post procedure as recommended by the guidelines. The second group of patients was administered with saline infusion of $12 \mathrm{ml} \cdot \mathrm{kg}^{-1} \cdot \mathrm{h}^{-1}$ during only CTO-PCI procedure, which is called as intensive infusion. None from angiography laboratory were informed about patients' group, and the infusion sets were covered, so that the saline flow speed was not visible.

\section{Statistical analyses}

SPSS for Windows v23.0 (Chicago, IL, USA) was used to perform all statistical analyses. Continuous variables were 
shown as mean and standard deviation, and categorical variables as the median with $25 \%-75 \%$. Group differences were analyzed using a $\chi^{2}$ test or Student's t-test/ Mann-Whitney $U$ test for categorical variables and continuous variables, respectively. To test normal distribution, a Kolmogorov-Smirnov test was used. A univariate logistic regression analysis was conducted for significant predictors. In addition, odds ratio (OR) and confidence interval (CI) were obtained. Regression analysis was conducted independently to predict the development of CIN. A $p$ value of less than 0.05 was considered statistically significant.

\section{Results}

One hundred twenty-eight subjects (mean age: $62.7 \pm$ 5 years) volunteered for this study. Approximately, 66\% were male $(n=84)$ and $43.4 \%(n=44)$ were female.

The demographic characteristics (age and gender) and coronary artery risk factors, previous CABG, PCI history, and dual injection as well as antegrade/ retrograde approach and infarct-related artery were similar in both groups. eGFR, SCr values, LVEF, and interventional lesion were similar in both groups. Baseline characteristics are shown in Table I. Angiographic characteristics, interventional procedure, CIN, amount of saline, amount of contrast, Mehran risk score, and successful procedure were similar in both the groups. There was a CIN development in nine patients (7.03\%). The CIN development was similar in two groups (the CIN development was observed in four patients in standard hydration group and in five patients in intensive hydration group). However, the amount of saline was significantly higher in the standard treatment group $(1,767 \pm 192.2$ vs. $1,043.6 \pm 375 ; p<0.001)$. Angiography, interventional methods, CIN, and medicine of the study population are shown in Table II. Evaluating the patients with and without CIN development during CTO-PCI procedure included assessing CIN development in the older people, body weight, LVEF, GFR, and higher Mehran risk scoring. The pre-procedural SCr values were higher and the post-procedural increase rates were higher in the group with CIN development. The characteristics of patients with and without CIN development during CTO-PCI procedure are summarized in Table III.

The OR and 95\% CI values are shown in Table IV. Age, body weight, diabetes mellitus (DM), saline concentration, LVEF, pre-procedure baseline (0), and post-procedure SCr were associated with CIN. Interestingly, age, LVEF, and DM independently predicted $\mathrm{CIN}(\mathrm{OR}=3.022,95 \% \mathrm{CI}=1.179-7.746, p=0.021$; $\mathrm{OR}=0.633,95 \% \mathrm{CI}=0.417-0.960, p=0.031$; and $\mathrm{OR}=0.007,95 \% \mathrm{CI}=0.002-0.350, p=0.019$, respectively) (Table $V$ ).
Table I Baseline demographic and clinical parameters of the study population

\begin{tabular}{|c|c|c|c|}
\hline Variables & $\begin{array}{l}\text { Standard } \\
\text { hydration } \\
(n=64)\end{array}$ & $\begin{array}{c}\text { Intensive } \\
\text { hydration } \\
(n=64)\end{array}$ & $\begin{array}{c}p \\
\text { value }\end{array}$ \\
\hline Age (years) & $61.8(37-71)$ & $63.3(49-71)$ & 0.094 \\
\hline $\begin{array}{l}\text { Gender: male } \\
{[n(\%)]}\end{array}$ & $44(68.8)$ & $40(62.5)$ & 0.457 \\
\hline $\mathrm{DM}[n(\%)]$ & $21(31.8)$ & $17(26.6)$ & 0.439 \\
\hline Smoking $[n(\%)]$ & $27(42.2)$ & $19(29.7)$ & 0.141 \\
\hline $\operatorname{HT}[n(\%)]$ & $44(68.8)$ & $48(75.0)$ & 0.432 \\
\hline CABG $[n(\%)]$ & $24(37.5)$ & $28(43.8)$ & 0.472 \\
\hline Prior PCI $[n(\%)]$ & $21(32.8)$ & $17(26.6)$ & 0.439 \\
\hline Dual $[n(\%)]$ & $27(42.2)$ & $29(45.3)$ & 0.722 \\
\hline Antegrade $[n(\%)]$ & $54(84.4)$ & $56(87.5)$ & 0.611 \\
\hline $\begin{array}{l}\text { Retrograde } \\
{[n(\%)]}\end{array}$ & $10(15.6)$ & $8(12.5)$ & 0.616 \\
\hline \multicolumn{4}{|c|}{ Infarct-related artery } \\
\hline $\operatorname{LAD}[n(\%)]$ & $30(46.9)$ & $31(48.4)$ & \\
\hline $\mathrm{CX}[n(\%)]$ & $6(9.4)$ & $6(9.4)$ & 0.935 \\
\hline $\operatorname{RCA}[n(\%)]$ & $27(42.2)$ & $25(39.1)$ & \\
\hline Greft $[n(\%)]$ & $1(1.6)$ & $2(3.1)$ & \\
\hline Kilograms (kg) & $73.6 \pm 8.0$ & $75.9 \pm 9.5$ & 0.140 \\
\hline LVEF (\%) & $50.0 \pm 6.0$ & $51.6 \pm 6.7$ & 0.144 \\
\hline $\mathrm{SCr}(0)(\mathrm{mg} / \mathrm{dl})$ & $1.0 \pm 0.1$ & $1.0 \pm 0.1$ & 0.954 \\
\hline $\operatorname{SCr}(\mathrm{l})(\mathrm{mg} / \mathrm{dl})$ & $1.1 \pm 0.2$ & $1.1 \pm 0.3$ & 0.536 \\
\hline $\operatorname{SCr}(2)(\mathrm{mg} / \mathrm{dl})$ & $1.1 \pm 0.2$ & $1.1 \pm 0.2$ & 0.658 \\
\hline $\begin{array}{l}\text { GFR } \\
(\mathrm{ml} / \mathrm{min})\end{array}$ & $78.1 \pm 18.4$ & $77.1 \pm 16.3$ & 0.736 \\
\hline $\operatorname{BMI}\left(\mathrm{kg} / \mathrm{m}^{2}\right)$ & $26.0 \pm 3.5$ & $25.5 \pm 3.7$ & 0.516 \\
\hline $\operatorname{LDL}(\mathrm{mg} / \mathrm{dl})$ & $117.3 \pm 21.2$ & $119.5 \pm 20.0$ & 0.534 \\
\hline $\operatorname{HGB}(\mathrm{g} / \mathrm{dl})$ & $12.8 \pm 1.2$ & $12.8 \pm 1.3$ & 0.874 \\
\hline
\end{tabular}

BMI: body mass index; CABG: coronary artery bypass grafting; SCr: serum creatinine; $(0)$ : before the procedure; $(1)$ : after the 12 th $h$; (2): after the 48th h; GFR: glomerular filtration rate; Cx: circumflex artery; DM: diabetes mellitus; HGB: hemoglobin; HT: hypertension; LAD: left anterior descending artery; LDL: low-density lipoprotein; LVEF: left ventricular ejection fraction; PCI: percutaneous coronary intervention; RCA: right coronary artery

\section{Discussion}

CIN is a severe impediment due to administration of iodinated contrast media during angiographic procedures [22-24]. Based on previous reports, the CIN frequency is roughly $13 \%$ in coronary intervention. However, only few reports have shown that the CIN prevalence in the intervention of CTO-CIN is typically a transient/reversible form of ARF [25]. In addition, CIN development has been accompanied by longer 
Table II Angiographic characteristics, interventional procedure, CIN, and amount of medicine parameters of the study population

\begin{tabular}{lccc} 
Variables & $\begin{array}{c}\text { Standard } \\
\text { hydration } \\
(n=64)\end{array}$ & $\begin{array}{c}\text { Intensive } \\
\text { hydration } \\
(n=64)\end{array}$ & $p$ value \\
$\begin{array}{l}\text { Succesful } \\
\text { procedure } \\
{[n(\%)]}\end{array}$ & $53(82.8)$ & $52(81.3)$ & 0.818 \\
$\begin{array}{l}\text { Lesion length } \\
\begin{array}{l}\text { Fluoroscopy } \\
\text { time }\end{array}\end{array}$ & $31.8(5-42)$ & $32.2(24-41)$ & 0.889 \\
$\begin{array}{l}\text { Duration of } \\
\text { intervention }\end{array}$ & $91.6 \pm 15.9$ & $91.0 \pm 17.6$ & 0.656 \\
$\begin{array}{l}\text { Mehran score } \\
\begin{array}{l}\text { Dose of } \\
\text { furosemide }\end{array}\end{array}$ & $5.7 \pm 1.9$ & $5.5 \pm 2.1$ & 0.219 \\
$\begin{array}{l}\text { Amount of } \\
\text { saline }\end{array}$ & $1767.7 \pm 192.2$ & $1043.6 \pm 375.0<0.001$ \\
$\begin{array}{l}\text { Amount of } \\
\text { contrast }\end{array}$ & $300.9 \pm 25.8$ & $302.9 \pm 25.1$ & 0.658 \\
CIN & $4(6.25)$ & $0.55(0.3-3)$ & 0.153 \\
\hline
\end{tabular}

$\overline{\text { Bold values are significant at } p \text { value }<0.05 \text {. CIN: contrast-induced }}$ nephropathy

hospitalization, increased morbidity/mortality, and exorbitant costs.

In this study, the deterioration in CIN and renal functions was found to be significantly lower in standard and intensive hydration groups compared to those reported in the literature $(7.03 \%)$. However, patients with high and very high Mehran risk scoring for CIN development were excluded in this study; therefore, the risk scores of our patients were lower. Moreover, we conserved CIN development conducting hydration in both patient groups.

The patients, in whom CIN was developed during CTO-PCI procedure, were older and had lower body weight, lower LVEF, lower GFR, and higher Mehran risk scoring. Moreover, the pre-procedural SCr values were higher and the post-procedural increase rates were higher in the group with CIN development. These results were similar with literature studies conducted on angiography, PCI, and CTO-PCI patients in terms of CIN development.

CTO procedures are longer and more complex, so the use of large volumes of contrast medium is required. The most important factor determining both time and opaque use is operator experience. Our center is experienced and the CTO-PCI procedure has been conducted for about 5 years. Processing times, contrast amounts, fluoroscopic times, and success rates were similar with the studies conducted on these same issues [26-28].

It is extremely important in terms of cost-effectiveness to conduct hydration for $91 \mathrm{~min}$ in the intensive group and
Table III CTO-PCI result in CIN group and non-CIN group parameters of the study population

\begin{tabular}{|c|c|c|c|}
\hline Variables & CIN $(n=9)$ & $\begin{array}{l}\text { Non-CIN } \\
(n=119)\end{array}$ & $p$ value \\
\hline Age (years) & $68.89 \pm 2.2$ & $62.21 \pm 4.9$ & $<0.001$ \\
\hline $\begin{array}{l}\text { Gender: male } \\
{[n(\%)]}\end{array}$ & $6(66.7)$ & $39(86)$ & 0.090 \\
\hline $\mathrm{DM}[n(\%)]$ & $5(55.6)$ & $33(27.7)$ & 0.120 \\
\hline Smoking $[n(\%)]$ & $27(42.2)$ & $19(29.7)$ & 0.141 \\
\hline $\mathrm{HT}[n(\%)]$ & $4(44.4)$ & $32(26.9)$ & 0.271 \\
\hline $\mathrm{CABG}[n(\%)]$ & $4(44.4)$ & $48(40.3)$ & 0.811 \\
\hline $\begin{array}{l}\text { Prior PCI } \\
{[n(\%)]}\end{array}$ & $4(44.4)$ & $34(28.6)$ & 0.451 \\
\hline Kilograms (kg) & $74.33 \pm 8.3$ & $8122 \pm 12.9$ & 0.024 \\
\hline LVEF (\%) & $43.78 \pm 5.3$ & $50.63 \pm 6.4$ & 0.003 \\
\hline Time interval & $93.6 \pm 12.5$ & $91.18 \pm 17$ & 0.671 \\
\hline $\begin{array}{l}\text { Amount of } \\
\text { saline }\end{array}$ & $1,696.24 \pm 456$ & $1570.55 \pm 333$ & 0.291 \\
\hline $\begin{array}{l}\operatorname{SCr}(0) \\
(\mathrm{mg} / \mathrm{dl})\end{array}$ & $1.11 \pm 0.26$ & $1.0 \pm 0.13$ & 0.073 \\
\hline $\operatorname{SCr}(\mathrm{l})(\mathrm{mg} / \mathrm{dl})$ & $1.76 \pm 0.29$ & $1.0 \pm 0.21$ & $<0.001$ \\
\hline $\operatorname{SCr}(2)(\mathrm{mg} / \mathrm{dl})$ & $1.56 \pm 0.3$ & $1.1 \pm 0.19$ & $<0.001$ \\
\hline $\operatorname{GFR}(\mathrm{ml} / \mathrm{min})$ & $63.54 \pm 2.8$ & $78.33 \pm 17$ & $<0.001$ \\
\hline BMI $\left(\mathrm{kg} / \mathrm{m}^{2}\right)$ & $24.67 \pm 2.8$ & $25.8 \pm 3.6$ & 0.287 \\
\hline Mehran score & $7.78 \pm 1.9$ & $5.5 \pm 1.9$ & 0.001 \\
\hline $\begin{array}{l}\text { Dose of } \\
\text { furosemide }\end{array}$ & $0.44 \pm 07.2$ & $0.41 \pm 0.79$ & 0.900 \\
\hline $\mathrm{LDL}(\mathrm{mg} / \mathrm{dl})$ & $132.22 \pm 26.4$ & $117.4 \pm$ & 0.534 \\
\hline $\operatorname{HGB}(\mathrm{g} / \mathrm{dl})$ & $12.78 \pm 1.3$ & $12.87 \pm 1.1$ & 0.834 \\
\hline
\end{tabular}

Bold values are significant at $p$ value $<0.05$. CTO: chronic total occlusion; PCI: percutaneous coronary intervention; CIN: contrast-induced nephropathy; DM: diabetes mellitus; HT: hypertension; CABG: coronary artery bypass grafting; LVEF: left ventricular ejection fraction; SCr: serum creatinine; $(0)$ : before the procedure; (1): after the 12th h; (2): after the 48th h; GFR: glomerular filtration rate; BMI: body mass index; LDL: low-density lipoprotein; HGB: hemoglobin

$24 \mathrm{~h}$ in the standard group. The most important clinical outcome of this study was that there was a significant difference between intensive and standard groups in terms of saline amount (1,043 vs. 1,767 ml); on the other hand, CIN development was similar in both groups. Although the demographic characteristics and CIN development risk scores of patient groups were similar, this is an unexpected result, in which better outcomes in the group administered longer and more hydration was not observed. It is necessary to analyze the renal filtration functions and their mechanisms to explain this. The formation of reactive oxygen radicals, renal medullary ischemia due to vasoconstriction caused by contrast material, and direct tubular toxicity have been suggested in studies as mechanisms responsible for 
Table IV Factors associated with contrast-induced nephropathy

\begin{tabular}{lrrr} 
Variables & $\begin{array}{c}\text { Odds } \\
\text { ratio* }\end{array}$ & $\begin{array}{c}\text { 95\% confidence } \\
\text { interval* }\end{array}$ & $p$ value \\
Age $($ years $)$ & 0.008 & {$[0.001-0.015]$} & $\mathbf{0 . 0 2 5}$ \\
Gender & 0.114 & {$[-0.002-0.230]$} & 0.053 \\
Kilograms $(\mathrm{kg})$ & 0.006 & {$[0.002-0.011]$} & $\mathbf{0 . 0 4 2}$ \\
Time interval & 0.006 & {$[0.001-0.011]$} & 0.729 \\
BMI $\left(\mathrm{kg} / \mathrm{m}^{2}\right)$ & -0.013 & {$[-0.038-0.012]$} & 0.970 \\
HT & -0.009 & {$[-0.079-0.062]$} & 0.811 \\
DM & 0.212 & {$[0.099-0.325]$} & $<\mathbf{0 . 0 0 1}$ \\
Saline & -0.396 & {$[0.230-0.562]$} & $<\mathbf{0 . 0 0 1}$ \\
concentration & & & \\
LVEF $(\%)$ & -0.005 & {$[-0.013-0.020]$} & $\mathbf{0 . 0 2 2}$ \\
LDL $(\mathrm{mg} / \mathrm{dl})$ & 0.001 & {$[-0.003-0.005]$} & 0.330 \\
SCr $(0)(\mathrm{mg} / \mathrm{dl})$ & -0.825 & {$[-1.251-0.400]$} & $<\mathbf{0 . 0 0 1}$ \\
SCr $(1)(\mathrm{mg} / \mathrm{dl})$ & 0.884 & {$[0.658-1.109]$} & $<\mathbf{0 . 0 0 1}$ \\
SCr $(2)(\mathrm{mg} / \mathrm{dl})$ & 0.071 & {$[-0.209-0.351]$} & 0.617 \\
GFR & 0.002 & {$[-0.002-0.007]$} & 0.296 \\
Mehran score & -0.005 & {$[-0.022-0.011]$} & 0.524 \\
\hline
\end{tabular}

Bold values are significant at $p$ value $<0.05$. BMI: body mass index; DM: diabetes mellitus; $S C r$ : serum creatinine; $(0)$ : before the procedure; (1): after the 12th h; (2): after the 48th h; GFR: glomerular filtration rate; HT: hypertension; LDL: low-density lipoprotein; LVEF: left ventricular ejection fraction. ${ }^{*}$ Values were obtained by the univariate logistic regression analysis

Table V Multivariate logistic regression result for contrast-induced nephropathy

\begin{tabular}{lccc} 
Variables & $\begin{array}{c}\text { Odds } \\
\text { ratio }\end{array}$ & $\begin{array}{c}95 \% \text { confidence } \\
\text { interval }\end{array}$ & $\begin{array}{c}p \\
\text { value }\end{array}$ \\
Age & 3.022 & {$[1.179-7.746]$} & $\mathbf{0 . 0 2 1}$ \\
LVEF & 0.633 & {$[0.417-0.960]$} & $\mathbf{0 . 0 3 1}$ \\
$\begin{array}{l}\text { Saline } \\
\text { concentration }\end{array}$ & 1.003 & {$[1.000-1.007]$} & 0.073 \\
$\begin{array}{l}\text { DM } \\
\text { Creatinine }(0)\end{array}$ & 0.007 & {$[0.002-0.350]$} & $\mathbf{0 . 0 1 9}$ \\
$\begin{array}{l}\text { (mg/dl) } \\
\text { Creatinine }(1)\end{array}$ & 0.979 & {$[0.061-5.368]$} & 0.985 \\
$(\mathrm{mg} / \mathrm{dl})$ & & & \\
\hline
\end{tabular}

Bold values are significant at $p$ value $<0.05$. DM: diabetes mellitus; LVEF: left ventricular ejection fraction

contrast nephropathy pathophysiology [29]. In this study, tubular toxicity and medullary ischemia were prevented by preventing collapse of contrast media renal tubules collapse with intense hydration. Furthermore, the renal blood flow is maintained fairly constant, despite major changes in arterial blood pressure. This regulation is achieved by resistance changes in afferent and efferent arterioles.
Autoregulation and tubuloglomerular feedback are considered to be mechanisms that provide this adaptation [30]. In this study, we believe that the intensive hydration prevented renal injury by providing rapid disposal of contrast media from renal tubules due to decrease in resistance in afferent and efferent arterioles. The driving force in formation of glomerular filtration is the pressure difference between the glomerular capillaries and the Bowman's space in proximal tubules. The glomerular capillary pressure depends on the renal blood flow fed by cardiac output. Autoregulation is achieved with the resistance created by renal preglomerular afferent arterioles and postglomerular efferent arterioles [30]. Another effect of intensive hydration is to prevent renal injury and CIN development through rapid disposal of contrast media without much renal damage. This is done by high filtration speed caused by increased pressure in the Bowman's space. The administration of $1 \mathrm{ml} \cdot \mathrm{kg}^{-1} \cdot \mathrm{h}^{-1}$ saline infusion has similar effects on renal function. However, we believe that $12 \mathrm{ml} \cdot \mathrm{kg}^{-1} \cdot \mathrm{h}^{-1}$ saline administration allows kidney to perform all three mentioned filtration functions more quickly and adaptively.

\section{Study limitations}

The risk scores that determine CIN development of the patients were low and their renal function was normal or near normal. It is unclear whether intensive hydration will show similar effects especially in patients with moderateor high-risk scores for CIN development. When the patient population is considered, another limitation is that CTO occurs in older patients, in patients with renal function failure and in most cases, with LVEF deterioration. In this patient group, intensive hydration protocol may develop HF. In addition, in this study, although the diuretic requirement was statistically at a marginal value in the intensive hydration group, more diuretic need was observed in the intensive hydration group. Finally, the number of patients in this study was limited. There is a need for large randomized studies involving more patients with renal function failures and patients with high-risk scores for CIN development.

\section{Conclusions}

In recent years, PCI on CTO lesions has increased with technical developments and increased operator experience. The CIN development risk was increased for this patient group due to older ages, renal function failures, and excessive exposure to contrast in the CTO-PCI procedure. Intensive hydration administration appears to be an effective and cost-effective method in CTO-PCI patients, especially in patients without LV function failure. 
Funding sources: The founding sponsors had no role in the design of the study; in the collection, analyses, or interpretation of data; in the writing of the manuscript; and in the decision to publish the results.

Authors' contribution: EA, LA, and HT prepared the manuscript. ST and KEU gathered data. EK and OT searched the literature. EA, LA, and OT analyzed the data. All authors read and approved the final version of the manuscript.

Conflict of interest: The authors declare that there is no conflict of interest regarding the publication of this paper.

\section{References}

1. Sianos G, Werner GS, Galassi AR, Papafaklis MI, Escaned J, Hildick-Smith D: EuroCTO Club. Recanalisation of chronic total coronary occlusions: 2012 consensus document from the EuroCTO club. EuroIntervention 8, 139-145 (2012)

2. Carlino M, Magri CJ, Uretsky BF, Brilakis ES, Walsh S, Spratt JC, Hanratty C, Grantham JA, Rinfret S, Thompson CA, Lombardi WL, Galassi AR, Sianos G, Latib A, Garbo R, Karmpaliotis D, Kandzari DE, Colombo A: Treatment of the chronic total occlusion: A call to action for the interventional community. Catheter Cardiovasc Interv 85, 771-778 (2015)

3. Fefer P, Knudtson ML, Cheema AN, Galbraith PD, Osherov AB, Yalonetsky S: Current perspectives on coronary chronic total occlusions: The Canadian Multicenter Chronic Total Occlusions Registry. J Am Coll Cardiol 59, 991-997 (2012)

4. Jeroudi OM, Alomar ME, Michael TT, El Sabbagh A, Patel VG, Mogabgab O: Prevalence and management of coronary chronic total occlusions in a tertiary veterans affairs hospital. Catheter Cardiovasc Interv 84, 637-643 (2014)

5. Christofferson RD, Lehmann KG, Martin GV, Every N, Caldwell JH, Kapadia SR: Effect of chronic total coronary occlusion on treatment strategy. Am J Cardiol 95, 1088-1091 (2005)

6. Chung CM, Nakamura S, Tanaka K, Tanigawa J, Kitano K, Akiyama T: Effect of recanalization of chronic total occlusions on global and regional left ventricular function in patients with or without previous myocardial infarction. Catheter Cardiovasc Interv 60, 368-374 (2003)

7. Nakamura S, Muthusamy TS, Bae JH, Cahyadi YH, Udayachalerm $\mathrm{W}$, Tresukosol D: Impact of sirolimus-eluting stent on the outcome of patients with chronic total occlusions. Am J Cardiol 95, 161-166 (2005)

8. Baks T, van Geuns RJ, Duncker DJ, Cademartiri F, Mollet NR, Krestin GP: Prediction of left ventricular function after drug-eluting stent implantation for chronic total coronary occlusions. J Am Coll Cardiol 47, 721-725 (2006)

9. Cheng AS, Selvanayagam JB, Jerosch-Herold M, van Gaal WJ, Karamitsos TD, Neubauer S: Percutaneous treatment of chronic total coronary occlusions improves regional hyperemic myocardial blood flow and contractility: Insights from quantitative cardiovascular magnetic resonance imaging. JACC Cardiovasc Interv 1, 44-53 (2008)

10. Cetin M, Zencir C, Cakici M, Yildiz E, Tasolar H, Balli M: Effect of a successful percutaneous coronary intervention for chronic total occlusion on parameters of ventricular repolarization. Coron Artery Dis 25, 705-712 (2014)

11. George S, Cockburn J, Clayton TC, Ludman P, Cotton J, Spratt J, British Cardiovascular Intervention Society; National Institute for Cardiovascular Outcomes Research: Long-term follow-up of elective chronic total coronary occlusion angioplasty: Analysis from the U.K. Central Cardiac Audit Database. J Am Coll Cardiol 64, 235-243 (2014)
12. Claessen BE, Dangas GD, Godino C, Henriques JP, Leon MB, Park SJ: Multinational CTO Registry. Impact of target vessel on long-term survival after percutaneous coronary intervention for chronic total occlusions. Catheter Cardiovasc Interv 82, 76-82 (2013)

13. Galassi AR, Sianos G, Werner GS, Escaned J, Tomasello SD, Boukhris M, Euro CTO Club: Retrograde recanalization of chronic total occlusions in Europe: Procedural, in-hospital, and long-term outcomes from the Multicenter ERCTO registry. J Am Coll Cardiol 65, 2388-2400 (2015)

14. Aguiar-Souto P, Ferrante G, Del Furia F, Barlis P, Khurana R, Di Mario C: Frequency and predictors of contrast-induced nephropathy after angioplasty for chronic total occlusions. Int J Cardiol 139, 68-74 (2010)

15. Parfrey P: The clinical epidemiology of contrast-induced nephropathy. Cardiovasc Intervent Radiol 28, S3-S1 1 (2005)

16. Mehran R, Nikolsky E: Contrast-induced nephropathy: Definition, epidemiology, and patients at risk. Kidney Int Suppl 100, S11-S15 (2006)

17. Marenzi G, Marana I, Lauri G, Assanelli E, Grazi M, Campodonico $\mathrm{J}$ : The prevention of radiocontrast-agent-induced nephropathy by hemofiltration. N Engl J Med 349, 1333-1340 (2003)

18. Gupta R, Birnbaum Y, Uretsky BF: The renal patient with coronary artery disease: Current concepts and dilemmas. J Am Coll Cardiol 44, 1343-1353 (2004)

19. Bradley OJ, Paul BW, Richard W: Acetylcysteine in the prevention of contrast-induced nephropathy after coronary angiography. Am Heart J 146, E23 (2003)

20. McCullough PA, Adam A, Becker CR, Davidson C, Lameire N, Stacul F: Epidemiology and prognostic implications of contrastinduced nephropathy. Am J Cardiol 98, 5-13 (2006)

21. Mehran R, Aymong ED, Nikolsky E, Lasic Z, Iakovou I, Fahy M: A simple risk score for prediction of contrast-induced nephropathy after percutaneous coronary intervention: Development and initial validation. J Am Coll Cardiol 44, 1393-1399 (2004)

22. McCullough PA, Wolyn R, Rocher LL, Levin RN, O’Neill WW: Acute renal failure after coronary intervention: Incidence, risk factors, and relationship to mortality. Am J Med 103, 368-375 (1997)

23. Dangas G, Iakovou I, Nikolsky E, Aymong ED, Mintz GS, Kipshidze NN: Contrast-induced nephropathy after percutaneous coronary interventions in relation to chronic kidney disease and hemodynamic variables. Am J Cardiol 95, 13-19 (2005)

24. Rihal CS, Textor SC, Grill DE, Berger PB, Ting HH, Best PJ: Incidence and prognostic importance of acute renal failure after percutaneous coronary intervention. Circulation 105, 2259-2264 (2002)

25. Perrin T, Descombes E, Cook S: Contrast-induced nephropathy in invasive cardiology. Swiss Med Wkly 142, w13608 (2012)

26. Lin YS, Fang HY, Hussein H, Fang CY, Chen YL, Hsueh SK: Predictors of contrast-induced nephropathy in chronic total occlusion percutaneous coronary intervention. EuroIntervention 9, 1173-1180 (2014)

27. Mohammed NM, Mahfouz A, Achkar K, Achkar K, Rafie IM, Hajar R: Contrast-induced nephropathy. Heart Views 14, 106-116 (2013)

28. Wyatt CM, Camargo M, Coca SG: Prophylactic hydration to prevent contrast-induced nephropathy: Much ado about nothing? Kidney Int 92, 4-6 (2017)

29. Lameier NH: Contrast-induced nephropathy - Prevention and risk reduction. Nephrol Dial Transplant 2, 11-23 (2006)

30. Nishiyama A, Jackson KE, Majid DS, Rahman M, Navar LG: Renal interstitial fluid ATP responses to arterial pressure and tubuloglomerular feedback activation during calcium channel blockade. Am J Physiol Heart Circ Physiol 290, 772-777 (2006) 